\title{
Managing the transition from Vaisala RS92 to RS41 radiosondes within the Global Climate Observing System Reference Upper-Air Network (GRUAN): a progress report
}

\author{
Ruud J. Dirksen ${ }^{1}$, Greg E. Bodeker ${ }^{2}$, Peter W. Thorne ${ }^{3}$, Andrea Merlone ${ }^{4}$, Tony Reale ${ }^{5}$, Junhong Wang ${ }^{6}$, \\ Dale F. Hurst ${ }^{7,8}$, Belay B. Demoz ${ }^{9}$, Tom D. Gardiner ${ }^{10}$, Bruce Ingleby ${ }^{11}$, Michael Sommer ${ }^{1}$, Christoph von Rohden ${ }^{1}$, \\ and Thierry Leblanc ${ }^{12}$ \\ ${ }^{1}$ GRUAN Lead Centre, Deutscher Wetterdienst, Meteorologisches Observatorium Lindenberg, \\ Am Observatorium 12, 15848 Tauche/Lindenberg, Germany \\ ${ }^{2}$ Bodeker Scientific, 42 Russell Street, Alexandra 9320, New Zealand \\ ${ }^{3}$ Department of Geography Maynooth Co., Maynooth University, Kildare, Ireland \\ ${ }^{4}$ INRI, Turin, Italy \\ ${ }^{5}$ NOAA/NESDIS, Washington DC, USA \\ ${ }^{6}$ Department of Atmospheric and Environmental Sciences, State University of New York, Albany, USA \\ ${ }^{7}$ Global Monitoring Laboratory, NOAA Earth System Research Laboratories, Boulder, CO, USA \\ ${ }^{8}$ Cooperative Institute for Research in Environmental Sciences, University of Colorado, CO, USA \\ ${ }^{9}$ University of Maryland Baltimore County, 1000 Hilltop Circle, Baltimore, MD 21250, USA \\ ${ }^{10}$ Environmental Department, National Physical Laboratory, Hampton Rd, Teddington, Middlesex, TW11 OLW, UK \\ ${ }^{11}$ ECMWF, Shinfield Park, Reading, RG2 9AX, UK \\ ${ }^{12} \mathrm{JPL}$ - Table Mountain Facility, 24490 Table Mountain Road, Wrightwood, CA 92397, USA
}

Correspondence: Ruud J. Dirksen (ruud.dirksen@dwd.de)

Received: 4 October 2019 - Discussion started: 5 December 2019

Revised: 14 May 2020 - Accepted: 11 June 2020 - Published: 18 August 2020

\begin{abstract}
This paper describes the Global Climate Observing System (GCOS) Reference Upper-Air Network (GRUAN) approach to managing the transition from the Vaisala RS92 to the Vaisala RS41 as the operational radiosonde. The goal of GRUAN is to provide long-term highquality reference observations of upper-air essential climate variables (ECVs) such as temperature and water vapor. With GRUAN data being used for climate monitoring, it is vital that the change of measurement system does not introduce inhomogeneities to the data record. The majority of the 27 GRUAN sites were launching the RS92 as their operational radiosonde, and following the end of production of the RS92 in the last quarter of 2017, most of these sites have now switched to the RS41. Such a large-scale change in instrumentation is unprecedented in the history of GRUAN and poses a challenge for the network. Several measurement programs have been initiated to characterize differences in
\end{abstract}

biases, uncertainties, and noise between the two radiosonde types. These include laboratory characterization of measurement errors, extensive twin sounding studies with RS92 and RS41 on the same balloon, and comparison with ancillary data. This integrated approach is commensurate with the GRUAN principles of traceability and deliberate redundancy. A 2-year period of regular twin soundings is recommended, and for sites that are not able to implement this, burdensharing is employed such that measurements at a certain site are considered representative of other sites with similar climatological characteristics. All data relevant to the RS92RS41 transition are archived in a database that will be accessible to the scientific community for external scrutiny. Furthermore, the knowledge and experience gained regarding GRUAN's RS92-RS41 transition will be extensively documented to ensure traceability of the process. This documen- 
tation will benefit other networks in managing changes in their operational radiosonde systems.

Preliminary analysis of the laboratory experiments indicates that the manufacturer's calibration of the RS41 temperature and humidity sensors is more accurate than for the RS92, with uncertainties of $<0.2 \mathrm{~K}$ for the temperature and $<1.5 \% \mathrm{RH}$ (RH: relative humidity) for the humidity sensor. A first analysis of 224 RS92-RS41 twin soundings at Lindenberg Observatory shows nighttime temperature differences $<0.1 \mathrm{~K}$ between the Vaisala-processed temperature data for the RS41 ( $\left.T_{\mathrm{RS} 41}\right)$ and the GRUAN data product for

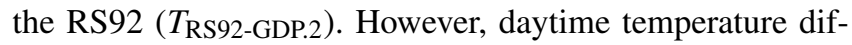
ferences in the stratosphere increase steadily with altitude, with $T_{\mathrm{RS} 92-\mathrm{GDP} .2}$ up to $0.6 \mathrm{~K}$ higher than $T_{\mathrm{RS} 41}$ at $35 \mathrm{~km}$. $\mathrm{RH}_{\mathrm{RS} 41}$ values are up to $8 \%$ higher, which is consistent with the analysis of satellite-radiosonde collocations.

\section{Introduction}

The Global Climate Observing System (GCOS) has instigated the GCOS Reference Upper-Air Network (GRUAN) (Bodeker et al., 2016) to perform reference quality measurements of upper-air essential climate variables (ECVs) (Bojinski et al., 2014).

The network consists of a range of national contributions of high-quality observing facilities that undertake observations in a systematically similar manner. The employed method of observation and subsequent data processing ensures traceability to International System of Units (SI) or community-accepted standards, with a full quantification of the uncertainties arising from every step in the processing chain. To date, the GRUAN data products for the Vaisala RS92 and the Meisei RS-11G radiosondes are the only ones currently being routinely produced and disseminated to the user community (Dirksen et al., 2014; Kizu et al., 2018). Several additional products, including those from other radiosonde models, ozonesondes, and a variety of remote sensing techniques, are at various stages of maturity and should be available for analysis in the near future. Readers interested in further details of GRUAN, its development, and its operation are encouraged to read Bodeker et al. (2016) or to visit the GRUAN website at https://www.gruan.org (last access: 23 July 2020). A map showing sites participating in GRUAN is shown in Fig. 1. Currently, RS92 data from GRUAN sites are available via anonymous ftp from the National Oceanic and Atmospheric Administration (NOAA) National Centers for Environmental Information at ftp://ftp.ncdc.noaa.gov/pub/data/gruan/processing/ level2/RS92-GDP/version-002 (last access: 23 July 2020).

In 2014, Vaisala announced the introduction of the RS41 as the RS92's successor and that the production of the RS92 radiosonde would be terminated by the end of 2017. Before its end of production, Vaisala's RS92 radiosonde was also widely used outside of GRUAN, with a global market share of approximately $30 \%$ (including at least daily launches at sites on every continent). Its performance was among the best of the commercially available radiosonde models (Nash et al., 2011). Until recently, the majority of the 27 GRUAN sites employed the RS92 (listed in Table 1 and shown in Fig. 1), which effectively made the RS92 GRUAN's backbone in terms of upper-air sounding. Any change in instrumentation in a GOS (Global Observing System) network not only presents potential data continuity concerns, but it also poses a challenge to a far broader community of users. Radiosounding data form a key input to numerical weather prediction (NWP) systems and human forecasts such that any change in performance has potentially large impacts. The challenge is to ensure continuity of operations without negative scientific or financial ramifications. The manual on the GOS states that "Changes of bias caused by changes in instrumentation should be evaluated by a sufficient period of observation (perhaps as much as a year) or by making use of the results of instrument intercomparisons made at designated test sites" (Sect. 2.2.2.13 of WMO, 2017).

One of the key potential benefits of a tiered network design (Bodeker et al., 2016) is the dissemination of information derived from a subset of top-tier reference quality sites down to the geographically broader lower-tier network sites. Figure 2 schematically depicts a three-tiered upper-air observing system architecture, with a 30-40 station GRUAN network providing reference observations for more extensive networks such as the GCOS upper-air network (GUAN). Reference network sites serve as long-term anchor points that comprehensively characterize the atmospheric column with the highest-quality measurements currently feasible. The base of the system is the entire global upper-air observing system, serving a wide variety of purposes, primarily weather prediction, including the operational radiosonde network as well as aircraft and satellite observations and embracing model-assimilated upper-air datasets and reanalyses. The 177-station (as of March 2019) GUAN is a subset of the operational radiosonde network that, in the late 1990s, committed to long-term, consistent observations but does not deploy any special instruments for high-quality climate observations as GRUAN does.

In the case of the transition from RS92 to other radiosonde types, the lessons learnt from GRUAN activities to manage the transition may benefit those GUAN sites faced with the same challenge as well as other sonde stations from the remainder of the GOS. Furthermore, by undertaking an intensive characterization of the transition, GRUAN can assist not just the climate community but also other communities, such as NWP and forecasting, through active dissemination of the resulting analyses of any effects of the transition. Such an approach requires visibility of the change management process and associated analysis results by the community through transparency of the GRUAN transition results, which will 
Table 1. List of GRUAN sites that are involved in the RS92-RS41 transition. Listed are the dates on which a site switched from RS92 to RS41 as the operational radiosonde for the sites, the length and frequency of the twin sounding programs, and the number of twin soundings performed (y - year, $\mathrm{m}$ - month, $\mathrm{w}$ - week, $\mathrm{d}$ - day, h - hour).

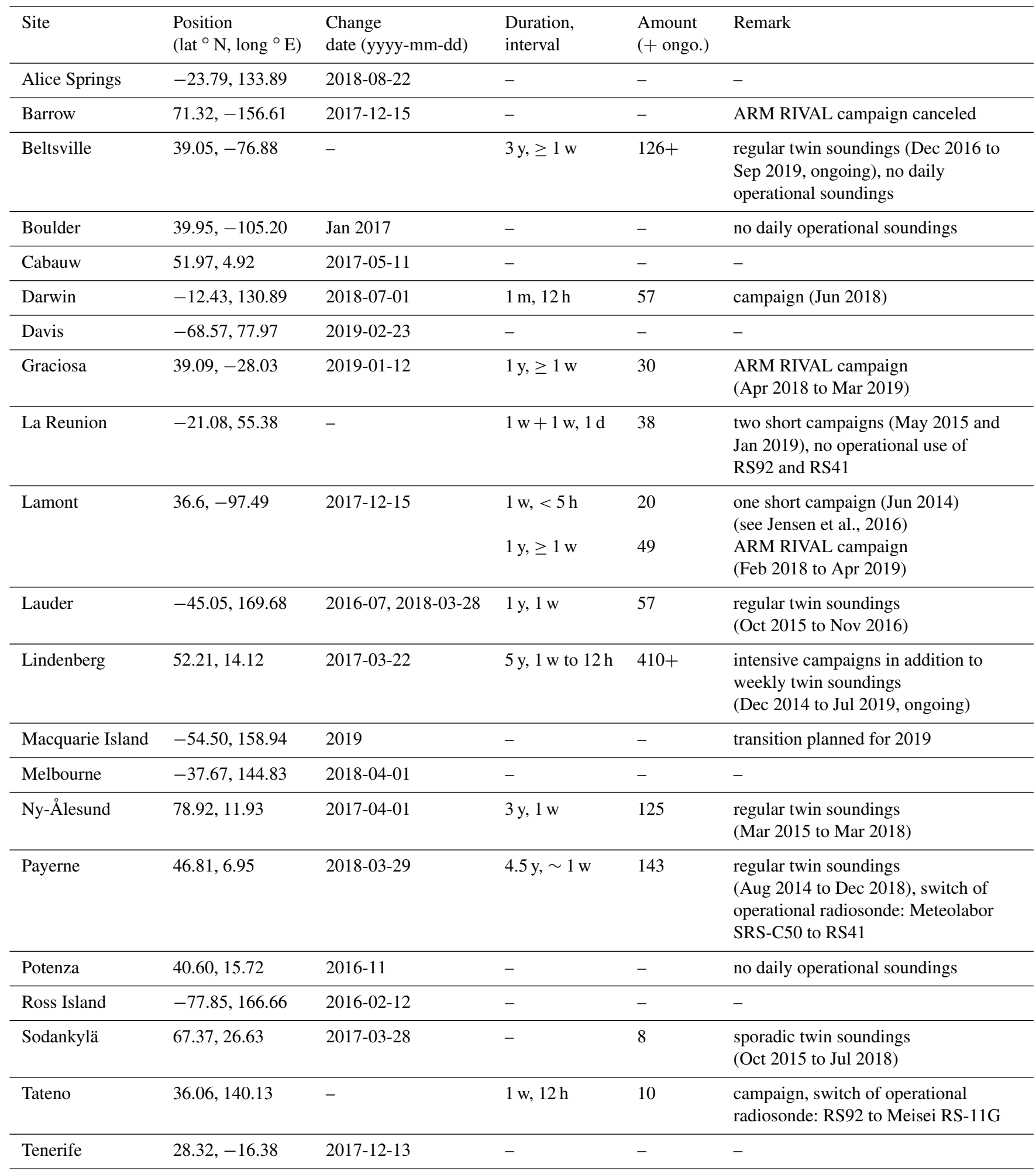




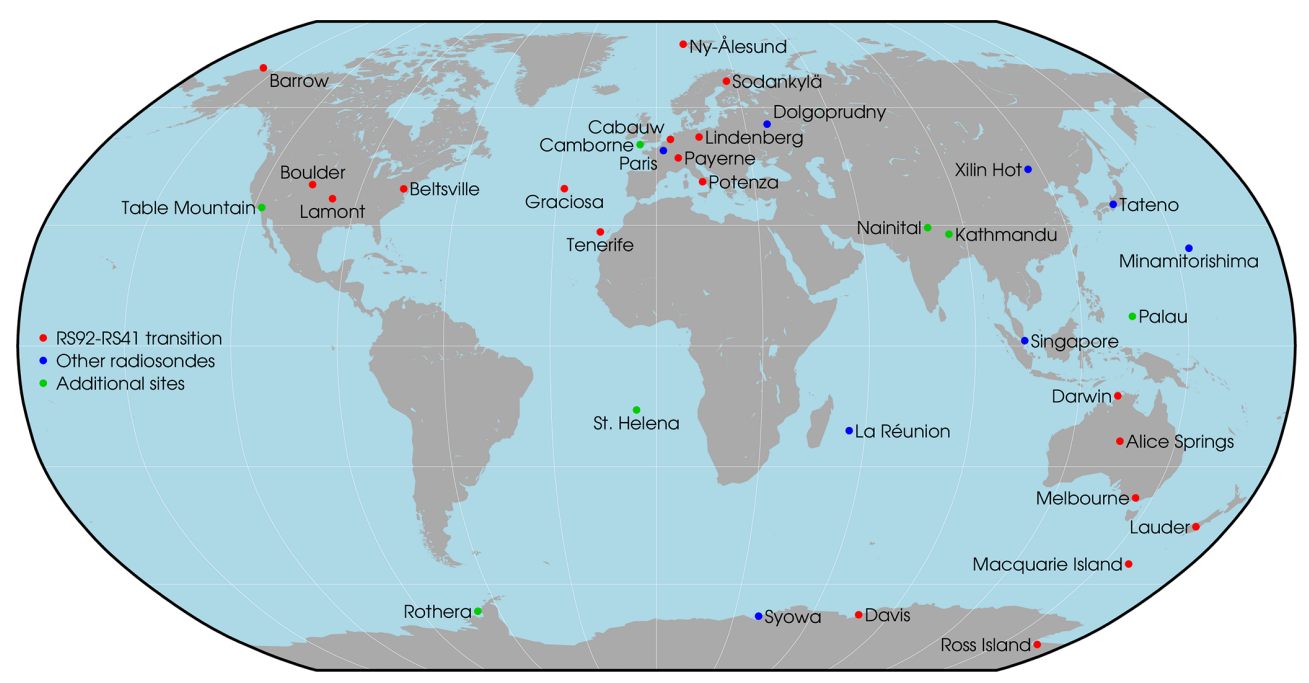

Figure 1. Locations of GRUAN sites and other transition-related sites (September 2019). Red dots represent sites that switched from RS92 to RS41 as their operational radiosonde. Blue dots represent sites that employ another type of radiosonde or that transitioned from another type to the RS41. Green dots represent sites which performed additional comparison launches and provided these data to GRUAN.

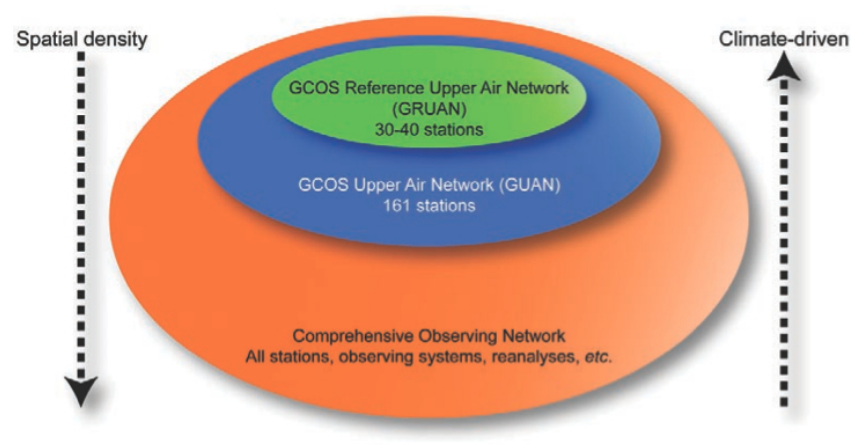

Figure 2. Schematic diagram of the GCOS tiered network concept of upper-air observations for climate. GRUAN offers less spatial density than either GUAN (a subset of the global radiosonde network stations that have made commitments of longevity and metadata collection) or the comprehensive network (which includes all ground-based and satellite upper-air observations and reanalyses) from Seidel et al. (2009).

provide the confidence required to encourage the uptake of the results.

This paper is a first step in this process and serves to highlight the activities undertaken to date and planned future activities that GRUAN (including the sites, Lead Centre, Working Group, and various task teams) intends to carry out in support of the change management. Community feedback, which may strengthen the planned activities, is strongly encouraged. In particular, we would eagerly welcome support with the following:

- the provision of available data from RS92+RS41 twin launches (i.e., both on the same balloon) from nonGRUAN sites to expand the geographical characteriza- tion of any biases between RS92 radiosondes and their successors;

- offers of assistance from the expert user community in the synthesis of twin launch data from multiple sites; and

- suggestions of additional analyses that could be performed.

The remainder of this paper outlines various aspects of the change strategy, such as a network-wide approach including burden-sharing, the application of ancillary data, the metrological perspective on the change, the role of documentation, and the creation of a scientific database that stores all measurement data relevant to the change. Furthermore, it reports on the progress to date and current plans to diagnose biases between the RS92 and RS41 radiosondes and provides some initial results based on analysis of 224 twin soundings that have been performed at the Lindenberg Observatory.

\section{The challenge}

For any long-term measurement series, inevitably, the challenge of change management is certain to arise. This could be either through choice when improved or more efficient means of making the measurements become available or by necessity as an instrument and its manufacturer support become unavailable. Regardless of whether by choice or necessity, the central challenge is to manage the transition in such a manner that the adverse effects on the continuity and homogeneity of a long-term measurement series are minimized and any uncertainties propagated by the transition are well 
understood. Sufficient data, and associated metadata, are required both to perform an initial analysis and to permit future reprocessing and reanalysis of the data.

Several national weather service (NWS) organizations implement change management strategies that are executed within their organization. An example of such an activity is the Radiosonde Replacement Plan for NOAA and the US NWS (see Peterson and Durre, 2004).

While GRUAN does its best to avoid unnecessary changes in its operating protocols, it is not immune from the challenges of change management. Change management has been a key component of the network's goal to constantly strive to make the best possible measurements of the relevant ECVs. As such, GRUAN has never been envisioned as a network for which the underlying instrumentation shall remain forever static. Prior to this forced transition away from RS92 sondes, only one GRUAN site (Tateno, Japan) had undergone a change in their radiosounding system, namely the switch from the Meisei RS2-91 to Vaisala's RS92 radiosonde in 2009-2010 (Kobayashi et al., 2012). This site subsequently switched from RS92 to Meisei RS-11G in 2015-2017.

In the case of the RS2-91 to RS92 switch, the change management included a series of twin launches during all four seasons. The study highlighted the importance of undertaking a sustained program (i.e., $>1$ year) of coincident soundings by old and new instrumentation to understand any seasonality of biases. Seasonally dependent biases may arise from changes in the measured ECVs and/or annual cycles of covariates such as radiation effects, which are particularly important at those sites where launches systematically occur at or near dusk and dawn. The second switch, RS92 to RS$11 \mathrm{G}$, involved 52 twin soundings over a period of 2 years (Kobayashi et al., 2019).

There are some crucial distinctions between this precursor analysis at Tateno and the current GRUAN-wide transition from RS92 to RS41 radiosondes. For Tateno, the following applies.

- At the time, neither the original nor the replacement sonde models had GRUAN data products being processed and provided routinely to the user community.

- The change related to a single instrument at a single site.

- The update arose from a choice by the site to change instrumentation such that the timetable could be altered as necessary.

Although the matter of broader change management pertaining to simultaneous instrument transitions at multiple sites has been informally discussed on various occasions, e.g., during GRUAN's annual Implementation and Coordination Meetings (ICMs), prior to the RS92 cessation of production, there was no formal plan for managing such a widespread change. This large-scale transition poses a major challenge for GRUAN as a reference network because it must not com- promise the continuity, quality, and homogeneity of the data records.

This change of the operational radiosonde at the majority of the GRUAN sites is unprecedented in the history of GRUAN. A network-wide challenge requires a facilitated and coordinated solution if the change is to be successful and if GRUAN is to succeed. The fundamental challenge is thus to design and deliver a GRUAN-wide strategy for managing and coordinating the near-simultaneous changes in the operational radiosonde at many sites. This strategy should include all aspects of the change management including, inter alia,

- network coordination to share the burden,

- the necessary roles of ancillary measurements coincident with the sonde measurements,

- instrument characterization in the laboratory and field under a wide range of conditions,

- scientific analysis,

- technical documentation and scientific publication,

- the dissemination of results to GRUAN and the broader GOS through GCOS/World Meteorological Organization (WMO) Integrated Global Observing System (WIGOS) mechanisms, and

- sharing information with agencies conducting near-realtime (NRT) data applications to aid their managing of the change.

Since GRUAN always seeks to promote competition in the marketplace, sites were encouraged to consider all available options for how to proceed with their transition from the RS92, including changing to sondes produced by other manufacturers. Despite the independent decision-making procedure, every GRUAN site that launched RS92 sondes has transitioned to the RS41. It is important to stress that these decisions arose from the individual GRUAN sites and not from the network management. The consequence is that the network must transition between two instrument models from the same manufacturer. If some sites had chosen to switch to radiosondes from different manufacturers, GRUAN would have been required to develop a very different change management program than the one described here.

Two of GRUAN's strengths are its ability to call on expertise from across the network to tackle such challenges and its ability to distribute required actions among the sites to share the burden. Currently, specialists from various fields of expertise within GRUAN are engaged in addressing the abovementioned points. This not only benefits the affected sites and GRUAN as a whole, but also helps other observational networks, such as GUAN, in managing the same transition. 


\section{Change management}

Proper management of the change of a measurement system requires determining all relevant differences between the two systems prior to the transition. Typically, this means organizing a period of observational system overlap as well as laboratory-based characterization of the differences between the instruments. While the specialized facilities to perform extensive laboratory testing are not available at each site, there is no impediment to sites performing real-world intercomparisons like twin soundings, although the costs of extra receiving systems and sondes may pose limits on the number of flights that can be performed.

It is essential to quantify biases between the new and old instruments as well as changes in calibration and/or measurement errors and uncertainties. These attributes may have complex interactions with covariates which complicate the quantification of the effects of the change. One example of such a measurement error, the solar-radiation-induced temperature bias, varies with altitude, season, and geographical location because it depends on the ambient pressure, solar elevation angle, and radiation intensity (Dirksen et al., 2014). The full range of sources of RS92 uncertainties that may have complex spatiotemporal characteristics, including ventilation, sensor orientation, and prelaunch calibration, has been described in detail by Dirksen et al. (2014). These uncertainties also vary with location due their dependence on solar elevation angle, cloudiness, and winds. Once the biases have been identified and corrected for, and the uncertainties have been determined, the data $\left(m_{1}\right.$ and $\left.m_{2}\right)$ from both measurement systems should be consistent, meaning that the agreement criteria set out in Eq. (1) are met with factor $k=2$ (Immler et al., 2010).

In other words, differences between coincident measurements by the two systems are consistently smaller than the $95 \%$ confidence interval.

$\left|m_{1}-m_{2}\right|<k \cdot \sqrt{u_{1}^{2}+u_{2}^{2}}$

Verifying this consistency requires a sufficient population of coincident measurements to determine that the data satisfy this condition in a statistically robust manner. Neither the GRUAN Manual (GCOS, 2013a) nor the GRUAN Guide (GCOS, 2013b) provide a clear requirement for the duration and intensity (measurement frequency) of an intercomparison study because it is inherently dependent on instrument type and measurement principle. However, as mentioned in Sect. 1, the manual on the GOS suggests a 1-year intercomparison period. Different instruments measure different ECVs in very distinct manners. Some are episodic remote sensing, some are continuous remote sensing, and others are periodic in situ profiles. For each measurement type a different "side-by-side" operation strategy would be required, which depends on (at a minimum) the instrument characteristics, variability in the target measurand, and cost and logistical considerations. Kobayashi et al. (2012) suggest that a total of 120 twin soundings spread across the seasonal cycle at a given location would be more than sufficient to characterize the effects of a change in radiosonde instrumentation, although the study did not consider the metrological quantification aspects that are necessary in the current case. Hence, for radiosondes, the GRUAN Lead Centre recommended that sites perform weekly, or with a 2-week interval, twin soundings for a period of 2 years. The 2-year period ensures that seasonality is better probed, and a sounding interval of a week instead of a day mitigates the additional operational costs. The twin soundings should be equally distributed between day and night soundings. The abovementioned metrological aspects refer to factors such as type B (instrumental) expanded uncertainties (absolute for each radiosonde), relative uncertainty in the comparison, traceability of involved instrumentation, and assessment of the comparability with independent ancillary results. This is the key aspect in adopting a metrological approach, whereby other reference instruments are used to make the evaluation traceable to standards and with a documented uncertainty budget.

Coordination with satellite overpass is highly encouraged, with particular emphasis on targeting times when a Global Navigation Satellite System radio occultation (GNSS-RO) and polar orbiter overpass may occur in the site's proximity. The sonde-satellite data comparison would also serve as an additional station-to-station transfer check of the consistency of the results. This is further discussed in Sect. 7 .

Laboratory testing is used to characterize the radiosonde's sensors, as is done to establish a GRUAN data product for each radiosonde model. The results of the laboratory tests for the RS92-RS41 transition are being employed in developing a GRUAN data product for the RS41. The parameters tested include radiation error for the temperature and humidity sensors, sensor calibration accuracy, and response time-lag and hysteresis effects of the humidity sensor. The Lead Centre facility, hosted by DWD at the Lindenberg Observatory, has access to a broad range of laboratory-based facilities suitable for characterizing radiosonde performance. These facilities, shown in Fig. 3, were used to characterize the RS92 instrument as described in Dirksen et al. (2014) and include the following:

- standard humidity chambers (SHCs) to validate RH sensor calibration,

- radiation test chambers to investigate the solar-induced temperature errors and dry biases, and

- a climate chamber operating between -75 and $+20^{\circ} \mathrm{C}$ for sensor response time-lag testing.

Section 5 gives a more detailed discussion of the application of these facilities to the characterization of radiosondes, together with an overview of preliminary results from these laboratory tests. 
(a)
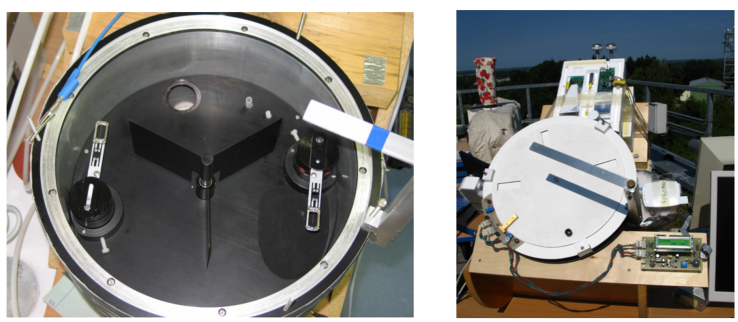

(c)
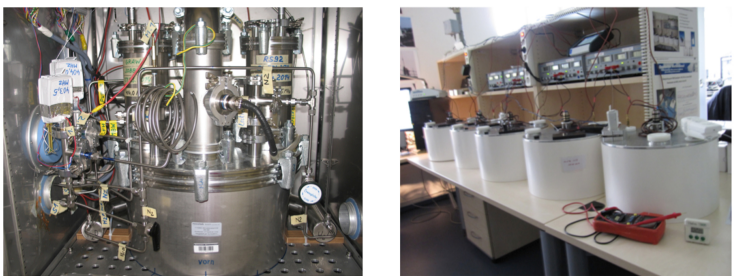

(d)

Figure 3. Overview of the experimental equipment used to characterize the measurement errors and uncertainties of the RS92 and RS41 sensors. (a) Radiation test chamber (top view). (b) Radiation test chamber in operation, oriented perpendicular to the Sun (light source). Visible on top of the quartz plate is the shutter, with three opening slits, allowing for simultaneous testing of three radiosondes. (c) Climate chamber that is used to test the performance of radiosondes under various temperature, pressure, and humidity conditions. In the configuration shown here, the response time lag of the humidity sensor is investigated. (d) Standard humidity chambers that contain reference saline solutions that generate $\mathrm{RH}$ environments between 0 and $100 \% \mathrm{RH}$.

\section{Network coordination to share the burden}

\subsection{Introduction}

From a GRUAN perspective, the collective transition from the RS92 to the RS41 radiosonde encourages approaches to burden-sharing this change management. Here, burdensharing means that selected sites, each representative of a different climate region (e.g., tropical, midlatitude, polar), perform prolonged intercomparison studies, while climatologically similar sites are not necessarily required to perform such campaigns. This reduces the logistical burden on the site and the cost of additional sondes and receiving systems. Other forms of burden-sharing could be implemented. For example, climatically equivalent sites can divide the workload such that one site conducts daytime twin flights, while another site performs nighttime twin flights. A similar division of labor could be agreed upon to balance sampling of different seasons.

This approach to burden-sharing will promote quality over quantity, as it is envisaged that some sites will opt only for a limited intercomparison period or perhaps only a short campaign-like effort. On their own, these limited intercomparison efforts would be insufficient to properly investigate the seasonality of the differences between the old and new sounding systems. But as a network, the sum of these small contributions becomes substantial. Table 1 lists the GRUAN sites that switched from RS92 to RS41 and, for those that decided to intercompare the two sondes, the actual or proposed duration and frequency of their twin sounding programs. Based on these results, the Arctic and the midlatitude climate regions in both hemispheres are covered by longterm intercomparison efforts. Clearly lacking are intercomparison efforts in the tropics and the Antarctic, a consequence of there being no GRUAN sites with an established operational RS92 measurement program in those regions. However, there is one (candidate) GRUAN site in the tropics that did employ the RS92 (the BoM-operated site in Darwin, Australia). This site has also decided to switch to RS41 and has performed a condensed intercomparison program, which partially fills the gap in the tropics.

In addition to the efforts by GRUAN sites, several nonGRUAN sites have also performed intercomparison campaigns as a way to manage their RS92-RS41 transition. These include the UK Met Office comparisons in St. Helena and Rothera in Antarctica. Some of these sites have agreed to share their twin sounding data with GRUAN, providing critical data in regions that are not covered by GRUAN sites. These sites are listed in Table 2. Furthermore, the GRUAN Lead Centre was involved in the StratoClim campaigns of 2016 and 2017 (India and Nepal, respectively; Brunamonti et al., 2018; Rex, 2014). During these campaigns that took place in July-August during the Indian monsoon, RS92RS41 twin soundings were performed to investigate the differences between the two systems under these particular meteorological conditions.

All data from the intercomparisons listed in Tables 1 and 2 will be made available to the scientific community via the GRUAN data servers, as discussed further in Sect. 8.3.

\subsection{Support equipment}

To support data telemetry for RS41 radiosonde measurements at GRUAN sites, the Lead Centre has a spare, fully equipped radiosounding receiving system that can be temporarily loaned to sites that cannot afford to purchase a second receiving station. This fully functioning system consists of an antenna, an MW41 receiving system, and a compact Vaisala WXT weather station for recording observations of surface meteorology (metadata) at the time of the launch. In addition to this hardware, an SHC can be loaned for performing manufacturer-independent prelaunch checks in a $100 \% \mathrm{RH}$ environment, as discussed by Dirksen et al. (2014).

Furthermore, Vaisala has several MW41 systems on hand that can be loaned to sites that wish to conduct short- to medium-term RS92-RS41 intercomparison campaigns. Various GRUAN sites have used this option to manage their transition, and loaned systems have also been employed during campaigns, such as the StratoClim campaigns and the CONCIRTO campaign on Reunion Island in 2019. 
Table 2. Non-GRUAN sites that provided data from RS92-RS41 intercomparison flights to GRUAN (y - year, $\mathrm{m}$ - month, w - week, $\mathrm{d}-$ day, h- hour).

\begin{tabular}{|c|c|c|c|c|}
\hline Site & $\begin{array}{l}\text { Position } \\
\left(\text { lat }^{\circ} \mathrm{N} \text {, long }{ }^{\circ} \mathrm{E}\right)\end{array}$ & $\begin{array}{l}\text { Duration, } \\
\text { interval }\end{array}$ & Amount & Remark \\
\hline Camborne & $50.22,-5.33$ & $\begin{array}{l}2 \mathrm{w},<6 \mathrm{~h} \\
7 \mathrm{~m}, \geq 1 \mathrm{w}\end{array}$ & 120 & $\begin{array}{l}\text { campaign organized by Vaisala in collaboration with } \\
\text { UK Met Office (Nov 2013), } 30 \text { flights with } 2 \times \text { RS } 92 \\
\text { and } 2 \times \text { RS41 on one rig (see Edwards et al., 2014) } \\
\text { regular twin soundings (Apr } 2018 \text { to Oct 2018) }\end{array}$ \\
\hline Kathmandu & $27.62,85.54$ & $2 \mathrm{w},<6 \mathrm{~h}$ & 28 & StratoClim campaign (Aug 2017) \\
\hline Nainital & $29.35,79.46$ & $1 \mathrm{~m}+1 \mathrm{w},<8 \mathrm{~h}$ & 35 & StratoClim campaign (Aug, Nov 2016) \\
\hline Palau & $7.34,134.47$ & $3 \mathrm{w}, 48 \mathrm{~h}$ & 20 & StratoClim campaign (Mar, Oct 2018, May 2019) \\
\hline Rothera & $-67.57,-68.13$ & $1 \mathrm{y}, \geq 1 \mathrm{w}$ & 48 & regular twin soundings (May 2017 to Aug 2018) \\
\hline St. Helena & $-15.94,-5.67$ & $1 \mathrm{y}, \geq 1 \mathrm{w}$ & 51 & regular twin soundings (Dec 2017 to Dec 2018) \\
\hline Table Mountain & $34.39,-117.7$ & $5 \mathrm{y}$, sporadic & 53 & sporadic twin soundings (2014 to 2018) \\
\hline Ship R/V Mirai & (cruise) & $5 \mathrm{~m}$, sporadic & 36 & $\begin{array}{l}\text { sporadic twin soundings (Aug to Dec 2015), } \\
\text { (see Kawai et al., 2017) }\end{array}$ \\
\hline
\end{tabular}

\section{Laboratory characterization}

\subsection{Introduction}

The laboratory facilities at the Lead Centre/Lindenberg Observatory, photographically presented in Fig. 3, are being used for extensive testing to characterize the measurement errors and uncertainties of the RS41 and the RS92, an activity which is essential for the development of GRUAN data products for both radiosondes. The tests primarily focus on the error sources which are known to be dominant for radiosondes, i.e., the solar radiation heating of the temperature and humidity sensors, and for the humidity sensor, i.e., its response time lag and the accuracy and reproducibility of its calibration.

Radiation error tests are performed in an adapted SHC at pressures between ambient and $3 \mathrm{hPa}$ (see Dirksen et al., 2014 , for a description of the radiation tests and their configuration) as well as in a newly developed system that allows for improved ventilation and illumination. Preliminary radiation tests were performed on RS41 radiosondes from 2014 through 2019, and further tests are foreseen for 2020. The results indicate that the temperature sensor of the RS41 radiosonde is less susceptible to heating by solar radiation than that of the RS92. However, these results apply to raw (uncorrected) measurement data, and it is not possible to draw direct conclusions on the resulting temperature bias between the Vaisala-processed data products of RS92 and RS41 since different corrections for radiative heating are applied to the two sonde models by the Vaisala processing software.

The calibration accuracy and hysteresis effects of the humidity sensor have been investigated by placing the radiosonde's sensor boom in an SHC with a stable, well- defined RH between $0 \%$ and $100 \%$. The stable RH environment inside each SHC is achieved using one of the saline mixtures listed in Table 3. In addition, each SHC is equipped with a Pt100 reference thermometer which tests the calibration accuracy of the radiosonde temperature sensor.

The reference Pt100 temperature sensors were certified by DAkkS (the German national accreditation agency), showing an uncertainty of $0.04 \mathrm{~K}(1 \sigma)$. The $\mathrm{RH}$ values over reference salt mixtures are taken from Greenspan (1977), who specifies the upper limit of the uncertainty of the employed $\mathrm{RH}$ values at $25^{\circ} \mathrm{C}$ as $0.5 \% \mathrm{RH}$.

The response time lag of the humidity sensor is determined by measuring its reaction to a stepwise change in the humidity of the airflow while keeping the temperature of the airflow constant. The time-lag effect becomes significant at temperatures below $-40^{\circ} \mathrm{C}$, the point at which the response time of the humidity sensor starts to exceed $10 \mathrm{~s}$ (Miloshevich et al., 2004; Dirksen et al., 2014). The time-lag tests are performed in a climate chamber which can reach temperatures as low as $-75^{\circ} \mathrm{C}$. Table 4 summarizes the laboratory experiments that have been performed to date to characterize the RS41 radiosonde.

The lab-based characterization results will be included in the scientific database holding all data that are relevant to the RS92 to RS41 transition (discussed in Sect. 8.3).

\subsection{Results of the laboratory characterization}

To assess the calibration accuracy of the humidity and temperature sensors, more than $150 \mathrm{RS} 41$ radiosondes from various production batches were tested in SHCs at the relative humidities listed in Table 3. In a typical experiment, each RS41 was sequentially placed in a series of six SHCs with 
Table 3. Humidity values achieved in the SHC using desiccant, pure water, and four different saturated salt solutions at $25^{\circ} \mathrm{C}$. The uncertainties of the RH values are given in parentheses. Data taken from Greenspan (1977). All radiosondes were tested twice at each RH level, except at $100 \% \mathrm{RH}$.

\begin{tabular}{lllllll}
\hline Relative humidity $(\% \mathrm{RH})$ & 0 & $11.30(0.27)$ & $33.78(0.18)$ & $75.29(0.12)$ & $97.30(0.45)$ & 100 \\
\hline SHC contents & desiccant & $\mathrm{LiCl}$ & $\mathrm{MgCl}$ & $\mathrm{NaCl}$ & $\mathrm{K}_{2} \mathrm{SO}_{4}$ & distilled $\mathrm{H}_{2} \mathrm{O}$ \\
\hline
\end{tabular}

Table 4. Overview of laboratory experiments performed at the GRUAN Lead Centre to characterize the RS41 sensors.

\begin{tabular}{lllll}
\hline Experiment & Sensor & Range & Setup & Time frame \\
\hline Radiation & $T, \mathrm{RH}$ & $3-1013 \mathrm{hPa}$ & radiation setup & $2014-2020$ \\
Time lag & $\mathrm{RH}$ & -75 to $-40^{\circ} \mathrm{C}$ & climate chamber & $2015-2020$ \\
Calibration & $\mathrm{RH}$ & $0 \%-100 \%$ & SHC, reference salts & since 2014 \\
\hline
\end{tabular}

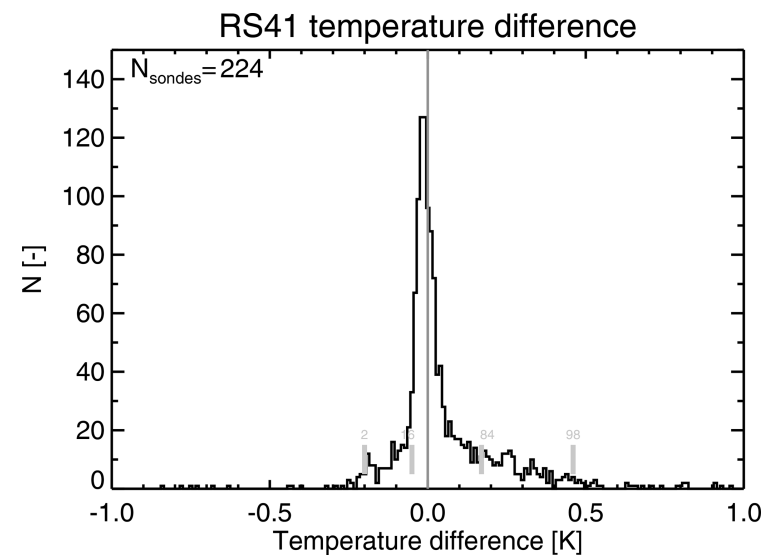

Figure 4. Histogram of the differences between the temperature recorded by the RS41 and the reference Pt100 probe at room temperature under various humidity conditions inside a standard humidity chamber. The plot displays the collated results for tests in $\mathrm{RH}$ environments of $0 \% \mathrm{RH}, 11 \% \mathrm{RH}, 33 \% \mathrm{RH}, 75 \% \mathrm{RH}$, and $100 \%$ RH (Table 3) that were performed between 2014 and 2018. Data are collected in $0.01 \mathrm{~K}$ bins. The grey bars indicate the percentiles that correspond to the boundaries of the $1 \sigma$ (16 and 84) and $2 \sigma(2$ and 98$)$ ranges.

increasing relative humidity, from $0 \%$ to $100 \%$, then back through the sequence of drier SHCs to $0 \% \mathrm{RH}$. This sequence also allows for the assessment of the hysteresis of the humidity sensor. At each humidity level, the radiosonde's sensor boom was inserted in the SHC for approximately 4 min while its readings were recorded. The air inside each SHC was circulated at $5 \mathrm{~m} \mathrm{~s}^{-1}$ by a fan, and the temperatures of the air and saline solution inside the SHCs were measured by Pt 100 reference thermometers. For some salts both air and solution temperatures are needed to accurately determine the relative humidity in the SHC, since the humidity over the reference salt depends on both quantities.

Figure 4 shows that the majority of the temperature measurements by the RS41 are within $\pm 0.5 \mathrm{~K}$ of the reference

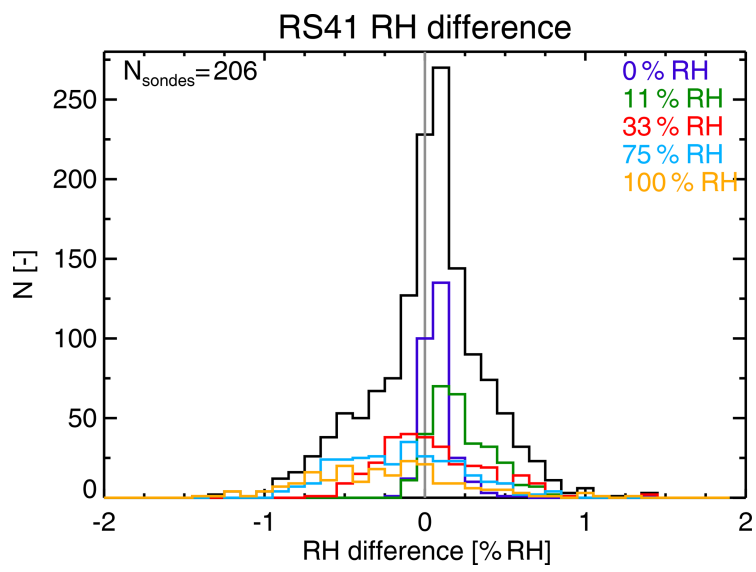

Figure 5. Histograms of the differences between the $\mathrm{RH}$ value recorded by the RS41 and the reference value at room temperature in the standard humidity chamber (Table 3 ) from tests that were performed between 2014 and 2018. The black trace represents the histogram of all measurements, and the colored traces represent the histograms for the reference RH values of $0 \% \mathrm{RH}$ (blue), $11 \% \mathrm{RH}$ (green), 33\% RH (red), $75 \%$ RH (light blue), and 100\% RH (orange). Data are collected in $0.1 \% \mathrm{RH}$ bins.

temperature. Although the tail of the distribution extends to $1 \mathrm{~K}$, fewer than $2 \%$ of the measurements show differences beyond $0.5 \mathrm{~K}$. The mode of the distribution indicates a bias of $-0.025 \mathrm{~K}$, while a calibration uncertainty of $<0.2 \mathrm{~K}(1 \sigma)$ can be inferred from the sensor's uncertainty $\pm 0.04 \mathrm{~K}$ and the 16th and 84th percentiles of the differences.

As is apparent from the percentile marks, the histogram of temperature differences between the RS41 and the Pt100 reference is not Gaussian, something that cannot yet be explained but will be the subject of further investigation.

Figure 5 shows that all humidity measurements by the RS41 are within $2 \% \mathrm{RH}$ of the SHC reference $\mathrm{RH}$ value, and only a small fraction of the measurements show differences larger than $1 \% \mathrm{RH}$. The uncertainty of the humidity calibra- 


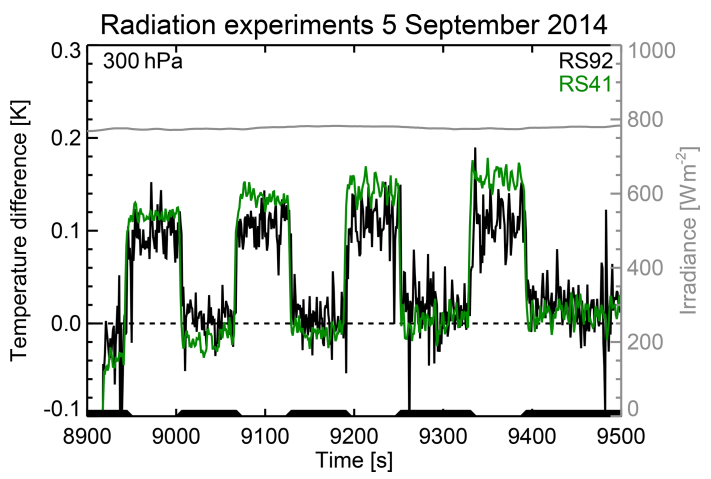

Figure 6. Results of radiation tests with the RS41 (green) and RS92 (black) radiosondes at $300 \mathrm{hPa}$ with $5 \mathrm{~m} \mathrm{~s}^{-1}$ ventilation flow. The solar irradiance during the test (thin grey trace) was approximately $800 \mathrm{~W} \mathrm{~m}^{-2}$. The thick black segments at zero temperature difference indicate when the shutter was closed. During shutter open periods the sensor was illuminated for $60 \mathrm{~s}$.

tion is $<1.5 \% \mathrm{RH}$ given the $<0.5 \% \mathrm{RH}$ uncertainties of the SHC RH references listed in Table 3.

The histograms of RH differences at the various RH levels, represented by the colored traces in Fig. 5, show that the calibration errors are dependent on RH. At low RH the differences and their spread are small, whereas at high RH the differences and spread are larger. As a result, the observed calibration errors at $0 \% \mathrm{RH}$ humidity cluster around $0 \%$ (blue trace in Fig. 5), thereby overrepresenting these values in the overall distribution (black trace in Fig. 5). The larger differences and spread at high RH indicate that there are discrepancies between the reference salt mixtures and the calibration by Vaisala.

Radiation tests were conducted in the modified SHC as described by Dirksen et al. (2014). Measurements were performed at various settings within the following ranges:

- pressure between $3 \mathrm{hPa}$ and ambient,

- irradiance from 200 to $1000 \mathrm{~W} \mathrm{~m}^{-2}$,

- ventilation speed of either 2.5 or $5 \mathrm{~m} \mathrm{~s}^{-1}$, and

- illumination times of 1-4 min.

The illumination times depended on pressure, with longer exposures required for lower-pressure environments to reach equilibrium. Figure 6 shows similar heating of the RS92 and RS41 temperature sensors at $300 \mathrm{hPa}(0.15 \mathrm{~K})$, but at $3 \mathrm{hPa}$ (Fig. 7) the RS41 (1.4K) heats only half as much as the RS92 $(2.8 \mathrm{~K})$. Furthermore, at $3 \mathrm{hPa}$, the RS41 sensor has reached equilibrium after approximately $30 \mathrm{~s}$ of illumination, whereas after $4 \mathrm{~min}$ of illumination the RS92 still has not reached equilibrium. The investigation of the RS41's radiation errors continues, including experiments with the newly developed laboratory radiation system, and the full analysis of these tests will be reported in a separate paper.

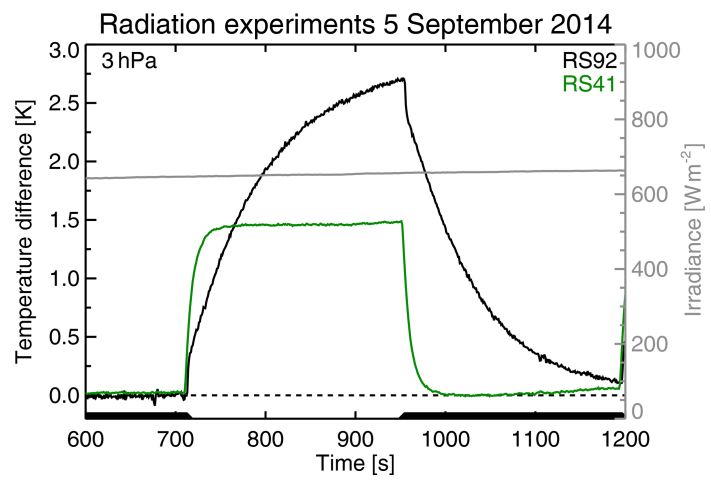

Figure 7. Results of radiation tests with the RS41 (green) and RS92 (black) radiosondes at $3 \mathrm{hPa}$ with $5 \mathrm{~m} \mathrm{~s}^{-1}$ ventilation flow. The solar irradiance during the test (thin grey trace) was approximately $650 \mathrm{~W} \mathrm{~m}^{-2}$. The thick black segments along the $x$ axis indicate when the shutter was closed. During shutter open periods the sensor was illuminated for $240 \mathrm{~s}$.

\section{Metrology}

A fundamental metrological principle stipulates that replacing one operational instrument with another should pose no problem provided that the results from both instruments are fully traceable to SI standards. Consequently, the new instrument could (almost) instantaneously be included in the traceability chain without the need for parallel testing or comparison with the replaced device. In practice, this idealized concept can rarely be adopted, even in primary metrology laboratories or in national metrology institutes. The problem is that different instruments or sensors may show different responses to external environmental factors.

Concerning radiosondes, the sensors, especially for humidity and temperature, may be exposed to unavoidable atmospheric or ascent-related effects during a sounding. Some of these effects cannot be completely duplicated during the controlled laboratory conditions which are provided during the preceding metrological instrument characterization and calibration procedures. Consequently, differences in the responses of sensors from different sonde models may still exist during ascents. An example is the warm bias of the radiosonde's temperature sensor caused by solar radiation.

For this reason it is essential to identify and quantify these differences between the old and new measurement system at each time of a sonde replacement, not only by laboratory work, but also by comparison flights during which the instruments are carried by the same balloon. The same should also be done when there have been significant changes in the design, sensor technology, or operation of an actual instrument.

An adequate characterization of the measurement uncertainties for entire radiosonde profiles includes the following components.

- Calibration uncertainty given by the manufacturer (see product data sheets for Vaisala RS92 and RS41 
available on the manufacturer's website: https://www. vaisala.com, last access: 24 July 2020). The sensors are calibrated in Vaisala's CAL4 calibration facility (Vaisala, 2002) that contains PTU (pressure, temperature, and humidity) reference sensors routinely recalibrated against NIST-traceable standards (for pressure and temperature; NIST - National Institute of Science and Technology of the United States of America) and the Finnish Centre for Metrology and Accreditation (Mittatekniikan keskus - MIKES, which has become part of the VTT Technical Research Centre of Finland Ltd and is now officially known as VTT-MIKES) for humidity. Note that for GRUAN the uncertainties of the calibration curves are important (not so much the information about the overall uncertainties in soundings which are related to the manufacturer-provided data product).

- Uncertainties from GRUAN-prescribed preflight ground check procedures.

- Uncertainties estimated during GRUAN postflight processing, including uncertainties of corrections to the measured raw data for systematic effects which are mainly derived from laboratory tests.

Differences revealed by instrument comparison flights indicate that some systematic effects have not yet been correctly assessed or even identified. To ensure consistency of the measurement results for different instruments, the differences are to be evaluated in terms of possible corrections, or, if this is not possible, the uncertainty budget is to be widened properly to account for them. It is important to arrange the comparisons network-wide in a coordinated manner, covering different seasons and locations. This is to ensure that all possible sources of systematic errors, such as latitude, climate, environmental and technical conditions before and during launch, and local specifics in the sounding procedures or setups, are tested during twin soundings.

An advantage of performing dual launches of RS92 and RS41 radiosondes is that some of the uncertainties related to the change process are moved from absolute evaluations to relative ones, making second-order contributions to the uncertainty budget limited if not negligible. Second-order contributions are uncertainties in the quantification of any environmental factor that affects the measurement of the primary quantity, like the intensity of solar radiation impinging on the temperature sensor.

The investigation of external environmental factors in the measurement uncertainty of meteorological instruments is one of the key elements of the MeteoMet project (Merlone et al., 2015, 2018), which also included dedicated campaigns for the validation of radiosonde data, for example in a polar environment (Musacchio et al., 2015).

\section{Ancillary measurements}

\subsection{Introduction}

Many GRUAN sites employ the principle of deliberate redundancy by simultaneously measuring a specific atmospheric parameter using different techniques. Examples include the use of remote sensing techniques such as the Global Navigation Satellite System (GNSS), lidar, microwave radiometer (MWR), or Fourier-transform infrared spectrometry (FTIR) in addition to the regular radiosonde flights. Ground-based observations, together with collocated satellite-based measurements, are referred to as ancillary data. These ancillary data significantly add to the analysis of the twin launch data because they provide an independent source of data unaffected by the same error sources as the radiosonde sensors, therefore allowing independent validation of the radiosonde intercomparison data.

Furthermore, within one orbit and among a limited number of consecutive orbits, satellites provide a consistent background on a global scale. However, the long-term calibration drifts and retrieval errors of spaceborne instruments must be taken into account when comparing long-term datasets of coincident radiosoundings and satellite overpasses (see, e.g., Hurst et al., 2016).

The GRUAN Lead Centre, in cooperation with the GRUAN Task Team on Ancillary Measurements, is working with each GRUAN site to establish respective ancillary measurement data streams and ascertain which of these streams contain relevant data that could be used to support the RS92 to RS41 transition. A key goal is to establish scheduling and sampling protocols to provide ancillary information that is spatially and temporally synchronized and internally consistent (Eq. 1). Protocols are being developed and deployed to ensure that such data are submitted to the scientific database (see Sect. 8.3) and tagged as ancillary information to facilitate future analyses.

The use of ancillary data from GRUAN sites in such a manner is currently in an early stage of development. Note that there are not yet certified GRUAN data products for the ancillary measurements, although some, like the GNSSbased total water vapor column product, are likely to be certified in the near future (Ning et al., 2016). Protocols for the development and delivery of geophysical profiles from the various remote sensing techniques are being finalized.

The NOAA Products Validation System (NPROVS) (Reale et al., 2012) facility routinely associates satellite measurements with GRUAN and operational observation data within a given spatiotemporal collocation window. This system can also process associated output from NWP models and profile data from coincident ancillary measurements, including their associated uncertainties. This facilitates redundancy testing (Immler et al., 2010) and the integration of consistent ancillary profiles into Site Atmospheric State Best Estimates (SASBE) (Tobin et al., 2006), which is another ob- 
jective of GRUAN. However, the processing, packaging, and integration of satellite, radiosonde, and ancillary data in a spatially and temporally coherent manner represent a complicated task that remains under discussion.

\subsection{Scheduling}

In addition to ground-based ancillary measurements such as GNSS, lidar, MWR, and FTIR, spaceborne observations from polar-orbiting radiometer sounders and satellite-based GNSS radio occultation (GNSS-RO) present a valuable and abundant source of redundant observations for comparisons with radiosounding data. To maximize their potential for scientific exploitation, the radiosonde launches should be scheduled to be coincident with satellite overpasses and/or the occurrence of GNSS-RO over the site.

Since the early 2000s, NOAA has cooperated with the US Department of Energy Atmospheric Radiation Measurement (ARM) program to perform radiosoundings that are collocated with satellite observations. A joint service between GRUAN and the European Organisation for the Exploitation of Meteorological Satellites (EUMETSAT) provides predictions of these overpasses, including so-called "golden overpasses" during which the measurements of a polar orbiter, such as MetOp-A or MetOp-B, are spatially (distance $<200 \mathrm{~km}$ ) and temporally (within $30 \mathrm{~min}$ ) collocated with a GNSS-RO measurement. In addition, at GRUAN sites where ground-based ancillary measurements are also being made, there could be multiple redundant observations of target ECVs to enable better exploitation; see Sect. 7.1 for a further discussion.

In the most basic context, satellites provide a consistent background or traveling calibration standard on a global scale to further interpret twin radiosonde results at a given site. Potential benefits include the identification of possible site bias and, in the case of twin soundings, a measure of the performance of the radiosondes in various atmospheric environments. The additional information from satellite-synchronized launches can potentially minimize the number of twin launches required, reducing costs for the sites and maximizing opportunities for subsequent exploitation by the broader science community for myriad applications on a global scale.

Figure 8 presents examples of the potential benefits from redundant observations compiled and processed using NPROVS.

Between September 2015 and November 2016, 58 RS92RS41 twin soundings were performed at the GRUAN site in Lauder, New Zealand. Among these, 15 were scheduled to coincide within $1 \mathrm{~h}$ with overpasses of EUMETSAT's MetOp-B satellite that hosts the Infrared Atmospheric Sounding Interferometer (IASI) and the Advanced Microwave Sounding Unit (AMSU).
The comparisons (Fig. 8) show that the wet bias in the upper troposphere between satellite and European Centre for Medium-Range Weather Forecasts (ECMWF) profiles and the Vaisala-processed radiosonde data is smaller for the RS41 radiosonde than for the RS92 radiosonde, meaning that the RS41 consistently reports higher RH values in the upper troposphere than the RS92. Both over Lauder and Europe, the water vapor levels measured by the RS41 are up to $10 \%$ higher than for the RS92. These results are consistent with Sun et al. (2016), who found that the bias of the water vapor mixing ratio in the upper troposphere (UT) from satellite observations and radiosonde measurements (from GRUAN and non-GRUAN sites) was at least $10 \%$ smaller for the Vaisala RS41 compared to RS92. This study was based on 6-month global samples of conventional RS41 and RS92 radiosondes collocated with spaceborne infrared and microwave soundings from NOAA's Suomi National Polar-orbiting Partnership (Suomi NPP) satellite.

The decreasing differences between the radiosonde and both the satellite and the model data is tentatively interpreted as the RS41 providing better RH measurements in the upper troposphere than the RS92. However, validation by additional independent measurements is needed to substantiate this.

Figure 8 also shows that the bias between radiosonde and satellite-model data in the UT is up to a factor of 2 smaller for Europe than for Lauder. In addition, the shapes of the difference profiles for Lauder and Europe are different, and analysis of this discrepancy is ongoing.

The finding that the RS41 measures higher humidity values in the UT than the RS92 is also consistent with results for RS92-RS41 twin soundings that were performed at the GRUAN site in Lamont-Southern Great Plains (SGP) in Oklahoma, USA, under the management of ARM (Jensen et al., 2016). However, these soundings were not collocated with satellite overpasses, so comparisons with satellite data are not possible.

The collocated observations also permit the assessment of calculated radiances derived from radiosonde profiles using radiative transfer models versus observed satellite radiances. Calbet et al. (2017) used this method to evaluate RS92 data, and when applying the same method to RS41 data it can provide additional information on the differences between RS92 and RS41.

In summary, scheduling and targeting RS41-RS92 twin soundings with satellite overpasses brings more systems into the comparison and can enhance the transition analysis and provide more robust physical interpretations of results under a wider variety of atmospheric conditions and locations. The NPROVS program provides routine coincidences of global conventional (including GUAN) and GRUAN reference radiosondes with environmental satellite observations (including GNSS-RO) within $6 \mathrm{~h}$ and $250 \mathrm{~km}$. These spatiotemporal criteria, taken from Reale et al. (2012), represent a compromise between representativeness and sample size. This estab- 

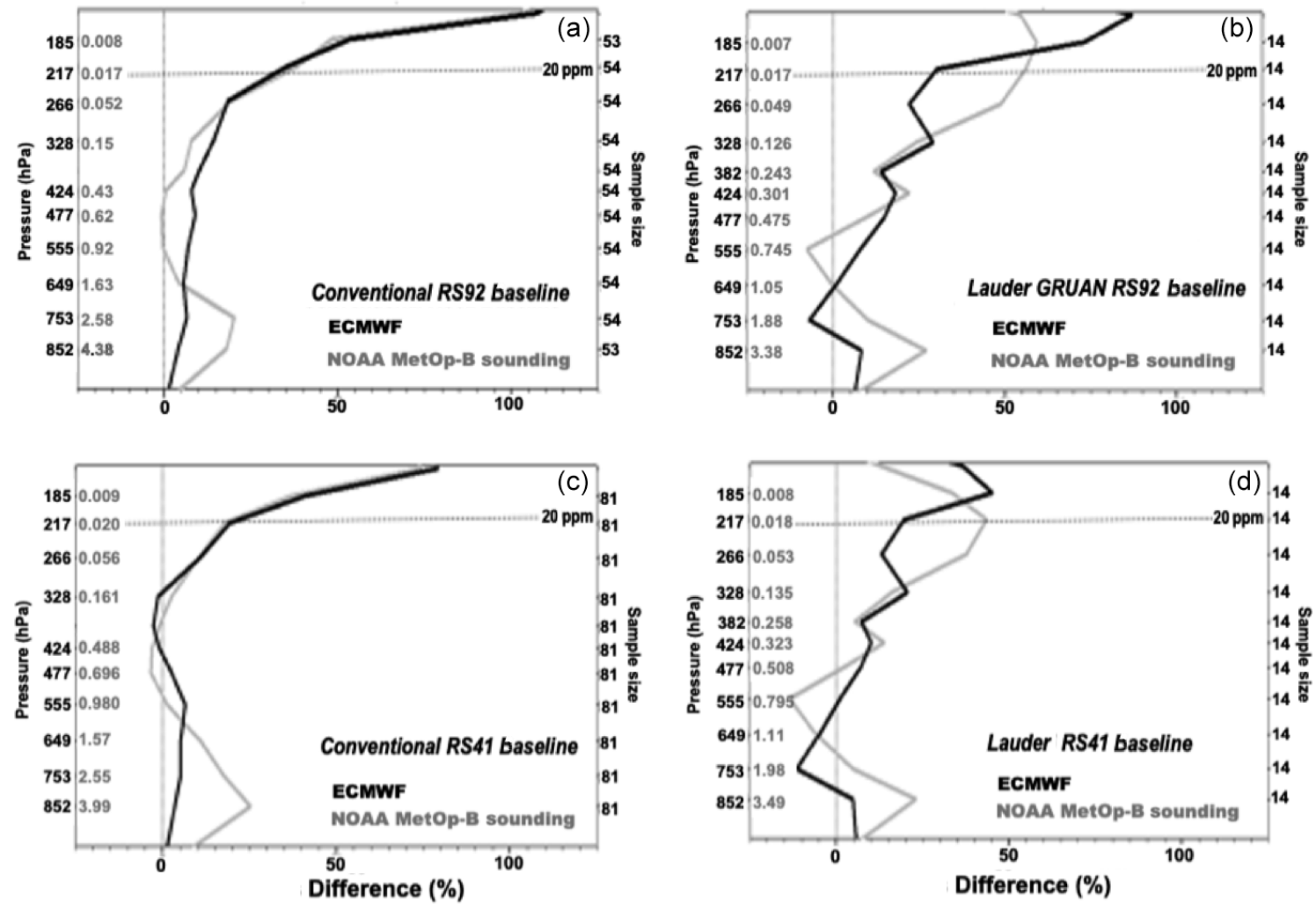

Figure 8. Mean biases between water vapor profiles from ancillary and radiosonde data from the RS92 (a, b) and RS41 (c, d). The relative differences are expressed as $100 \% \times\left(\mathrm{WVMR}_{\mathrm{anc}}-\mathrm{WVMR}_{\text {radiosonde }}\right) / \mathrm{WVMR}_{\text {radiosonde }}$ Grey trace: differences with satellite observations from IASI MetOp-B; solid black trace: differences with associated ECMWF analysis data. (b, d) The results for RS92-RS41 twin soundings performed at the GRUAN site in Lauder, New Zealand; only the RS92 data are GRUAN-processed. (a, c) The results for conventional RS92 and RS41 radiosoundings performed during a $10 \mathrm{~d}$ period in October-November 2017 at selected WMO sites in Europe $\left(35-65^{\circ} \mathrm{N}, 10^{\circ} \mathrm{W}-\right.$ $\left.40^{\circ} \mathrm{E}\right)$. Collocation criteria: less than $1 \mathrm{~h}(2 \mathrm{~h}$ for ECMWF data) at approximately $500 \mathrm{hPa}$ within $50 \mathrm{~km}$ at the surface. The labels at the $y$ axis depict the pressure level (black); the average water vapor mixing ratio $\left(\mathrm{g} \mathrm{kg}^{-1}\right)$ is given in grey. The numbers at the right-hand $y$ axis represent the number of coincident observations at each pressure level.

lishes a powerful baseline dataset which can then be subsampled for detailed analysis depending on specific requirements for synchronicity and cloudiness, for example.

\section{Scientific analysis and publication}

\subsection{Introduction}

The wide range of research activities investigating the RS92RS41 transition that are outlined in this paper will result in a substantive and valuable data archive.

The analysis of this data archive will be done from various perspectives by scientists with different areas of expertise. Their results will need to be shared with the atmospheric science community. Table 5 lists a preliminary allocation of research analysis tasks and their principal investigators. With this multidisciplinary approach to the analysis of the data it is anticipated that the differences between the RS41 and RS92 radiosondes will be well understood and that inhomo- geneities in their combined long-term data records can be minimized.

The list in Table 5 is incomplete and will be expanded as needs and requirements become clearer. The aim is to publish several distinct papers that describe the results. As further outlined in Sect. 9, we strongly welcome engagement by the broader atmospheric science community to analyze and publish the results.

\subsection{Preliminary results}

Up to September 2019, approximately 1500 RS92-RS41 twin soundings had been performed within GRUAN. A comprehensive analysis of this extensive dataset is still ongoing, but as an example of this larger effort we present the preliminary results of the twin soundings performed at Lindenberg. According to Table 1, more than 400 twin soundings were performed in Lindenberg between December 2014 and July 2019. A subset of 224 twin soundings was available for the current analysis. The majority of these were per- 
Table 5. List of scientific analysis tasks with their corresponding lead investigator(s).

\begin{tabular}{ll}
\hline Task & Lead \\
\hline Laboratory experiments & \\
\hline Radiation tests & Lead Centre \\
Time lag & Lead Centre \\
Development GRUAN data product for RS41 & Lead Centre \\
Twin soundings & Lead Centre + task team (TT) radiosonde \\
Ancillary measurements & TT ancillary measurements \\
NPROVS & Tony Reale \\
Metrology & Andrea Merlone \\
Statistical analysis & Alessandro Fasso \\
Evaluation of RS92-RS41 transition & Lead Centre/Working Group \\
\hline
\end{tabular}
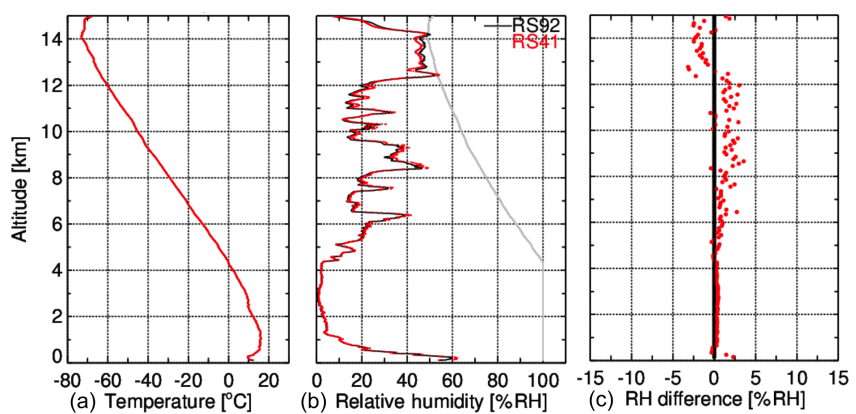

Figure 9. Twin sounding with RS92 and RS41 on the same balloon performed on 2 November 2015, 12:00 UTC, at Lindenberg Meteorological Observatory. (a) The observed temperature profile of RS92 (black) and RS41 (red). (b) The observed relative humidity profile over water; the grey trace represents ice saturation. (c) The differences between the humidity of the two sondes (RH41-RH92); the red dots represent data collected in $500 \mathrm{~m}$ altitude bins.

formed with a payload consisting of an RS92 and RS41 radiosonde only, but a substantial number were performed with the RS92 and RS41 as part of an expanded scientific payload that included a cryogenic frost-point hygrometer $(\mathrm{CFH})$ and an electrochemical concentration cell (ECC) ozonesonde. For the twin soundings, the payload rig was configured by conforming to the recommendations given in GRUAN-TN-7 (von Rohden et al., 2016) such that the radiosondes were attached with an $80 \mathrm{~cm}$ long string to each end of a $1.5 \mathrm{~m}$ long rod, ensuring free rotational movement of the radiosondes and minimizing potential contamination by water outgassing from the rod. In the analysis, GRUAN-processed RS92 profiles (RS92-GDP.2; Dirksen et al., 2014) are used, whereas the RS41 data are processed by the Vaisala MW41 system.

Figure 9 shows the profiles for such a twin sounding performed during daytime. The difference plot (panel c) shows that up to the tropopause (in this particular case at approximately $14 \mathrm{~km}$ ) both sondes capture the variations and structures in the humidity profile equally well, and the RS41 reports slightly higher (up to $2 \% \mathrm{RH}$ ) humidity values than the
RS92. Above the tropopause, the RS41 reports lower RH values than RS92, which is attributed to the shorter time lag of the RS41 humidity sensor that can more accurately measure the steep drop-off in water vapor as a function of altitude near the tropopause.

The plots in Fig. 10a show that for nighttime measurements the absolute temperature differences between the two sonde models are generally smaller than $0.05 \mathrm{~K}$ up to $30 \mathrm{~km}$ of altitude, with the RS92 (GRUAN-processed data) reporting slightly higher temperatures than RS41 (Vaisalaprocessed data). Above $30 \mathrm{~km}, T_{\mathrm{RS} 41}$ increasingly exceeds

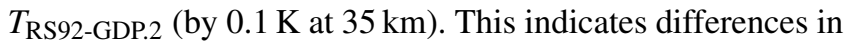
the corrections for radiative cooling at the top of the profile for each radiosonde type. Figure $10 \mathrm{~b}$ shows that the temperature differences for daytime measurements in the troposphere are smaller than $0.1 \mathrm{~K}$, with $T_{\mathrm{RS} 92-\mathrm{GDP} .2}$ larger than $T_{\mathrm{RS} 41}$. Above the tropopause these temperature differences gradually increase with altitude to approximately $0.6 \mathrm{~K}$ at $35 \mathrm{~km}$.

Figure 11 shows that the tropospheric humidity values in the Vaisala-processed RS41 data are on average up to $5 \%$ higher at night and up to $10 \%$ higher during daytime. For the daytime measurements (Fig. 11b) the relative differences increase with altitude, starting with a mean difference of $2.5 \%$ at the surface and reaching approximately $8 \%$ at $10 \mathrm{~km}$. This observed higher $\mathrm{RH}_{\mathrm{RS} 41}$ in the Lindenberg twin soundings is consistent with the results presented in Sect. 7.2 and in Fig. 8.

More detailed and elaborate analyses of the differences between RS92 and RS41, including twin soundings from other (GRUAN) sites, will be performed in subsequent studies. There are already a considerable number of data available, as is summarized in Tables 1 and 2. These studies will investigate in detail the influence of geographical and climatological effects, such as solar elevation angle, clouds, and winds, on the RS92-RS41 differences.

\subsection{Scientific database}

A dedicated database containing all data pertaining to the RS92-RS41 transition has been created and will be maintained. This database will be given its own digital object 

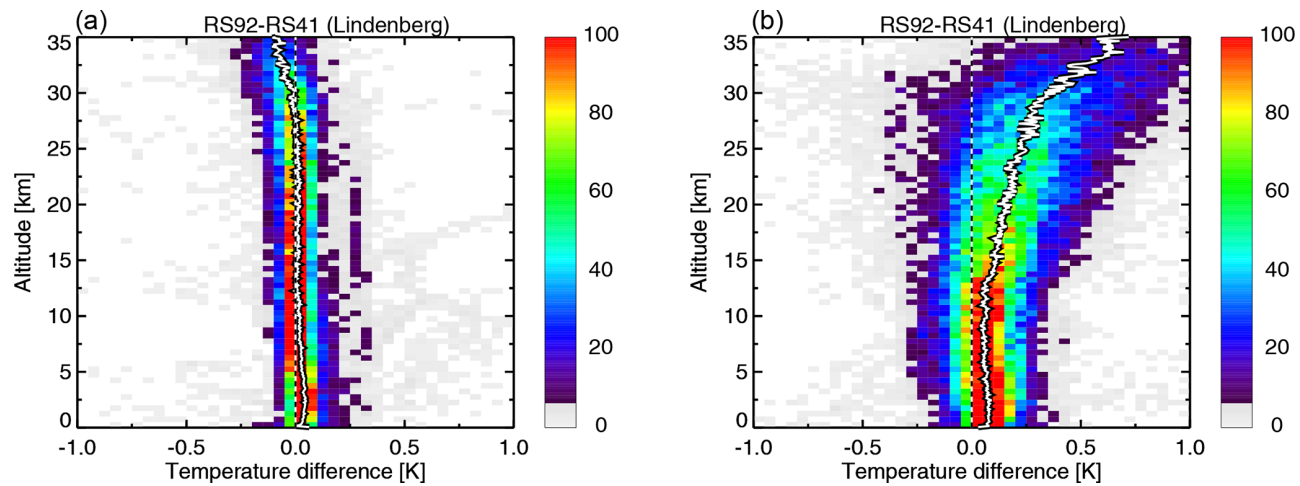

Figure 10. Temperature differences between the RS92 GRUAN data product (RS92-GDP.2) and Vaisala-processed RS41 data (RS92 ${ }_{\text {GDP.2- }}$

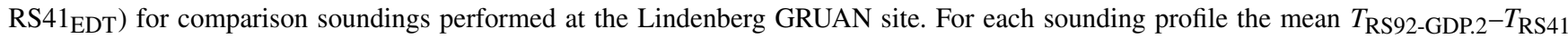
was calculated in a $500 \mathrm{~m}$ altitude bin. Data are presented as a scatter density plot in altitude-temperature bins of $0.5 \mathrm{~km} \times 0.05 \mathrm{~K}$. The color represents the number of data points in each bin. The thick white trace represents the averages of the temperature differences for each $500 \mathrm{~m}$ altitude bin. (a) The results for 77 nighttime soundings and (b) the results for 147 daytime soundings.
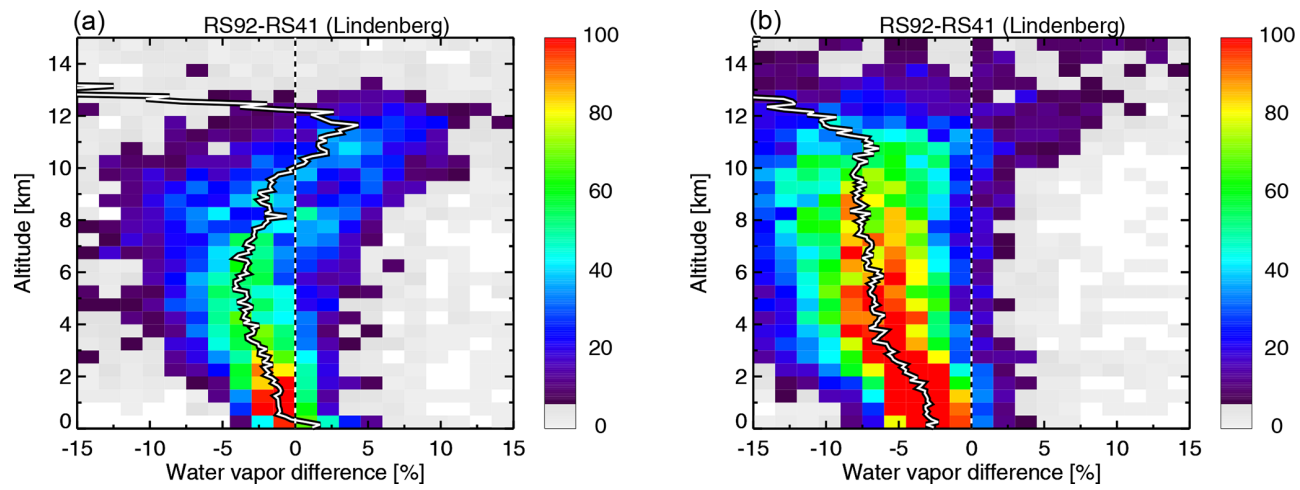

Figure 11. Same as Fig. 10 but for relative humidity. Shown is the relative difference $100 \times\left(\mathrm{RH}_{\mathrm{RS} 92-G D P .2}-\mathrm{RH}_{\mathrm{RS}}{ }_{1}\right) / \mathrm{RH}_{\mathrm{RS}} 92-\mathrm{GDP} .2$. The bin size for the scatter density plot is $0.5 \mathrm{~km} \times 2.5 \% \mathrm{RH}$. The average tropopause height over Lindenberg is approximately $10-12 \mathrm{~km}$.

identifier (DOI) and be preserved over the long-term. The purpose of the database is to have all relevant data for the transition available at a centralized location, thereby serving as a central point of access for users. This will facilitate a multifaceted analysis of the effects of the transition by experts from various fields of expertise.

The database will include data from laboratory measurements and intercomparison launches made at the sites. Furthermore, it will include coincident ancillary measurements from satellite overpasses and/or ground-based remote sensors such as those identified in Sect. 7. Making ancillary measurements available together with the radiosonde intercomparison data allows for an in-depth analysis and understanding of the differences between the RS92 and RS41 radiosondes, and it is consistent with one of the key principles of GRUAN: to have measurement redundancy.

The data format of the files in the ancillary database will be CF-compliant NetCDF for ease of access, and the database will be built for easy web-based data discovery and access. It will be available as it is being populated with data to enable scientific analysis from the outset.

Although it may not be possible to analyze all aspects of the data immediately, building a long-term database will enable exploitation by the expert community well into the future and represent a substantial value-added outcome. The database availability will be advertised via the GRUAN website at https://www.gruan.org (last access: 24 July 2020), and readers should check this source for the latest status.

\subsection{Technical documentation}

Documentation is a cornerstone of a reference network such as GRUAN. It is essential for the transfer of knowledge, ranging from describing operational procedures and best practices, to performing measurements via a detailed description of correction algorithms, to documenting changes to measurement systems. In a broader sense, robust documentation ensures the traceability of the data products, a requirement for reference data. Only through the existence of proper documentation is it possible to ensure the qual- 
ity of the measurement data within GRUAN. All GRUAN technical documentation is available on the GRUAN website under https://www.gruan.org/documentation/gruan/ (last access: 24 July 2020).

In the specific case of the RS92 to RS41 transition, comprehensive documentation will provide the required transparency on how the change was managed, and this will make it possible to reconstruct and scrutinize the reported differences between the RS92 and the RS41 radiosondes, even after many years. Furthermore, this documentation will serve as a template for managing any future transitions of measurement systems within GRUAN. Finally, with GRUAN documentation available to the wider scientific community, other networks, such as GUAN or the Global Observing System (GOS), might be assisted in managing changes in their observational radiosonde systems.

This paper serves as an overarching document, outlining the strategy of managing the RS92-RS41 transition within GRUAN. Other GRUAN technical documents and publications will cover various aspects in more detail. For example, a technical note was released which outlines the GRUAN recommendations for the rig configuration for performing twin soundings (von Rohden et al., 2016), whereas rig configurations for extended payloads consisting of multiple instruments and radiosondes are discussed in Jauhiainen et al. (2016). It is foreseen that separate papers will be written that report on the following:

- the results of the laboratory characterization of RS41 sensors described in Sect. 5,

- synthesis of the RS92-RS41 intercomparison studies, and

- comparison against non-radiosonde measurements (e.g., ancillary data).

In addition, a final paper will be drafted that collates and summarizes the results of the separate reports and summarizes and evaluates the outcomes of the RS92-RS41 transition for GRUAN.

\section{How to get involved}

The GRUAN change management program envisaged in this paper could, in principle, be completed solely by current GRUAN members (sites, Lead Centre, scientists in the Working Group on GRUAN, and task teams). However, we explicitly recognize that there are substantial resources and expertise beyond the immediate GRUAN community which could increase the robustness of all aspects of the envisaged program. Some specific potential suggestions are given below, but there are undoubtedly many more ways to get involved.

The participation of non-GRUAN sites planning to undertake an intercomparison of their own is strongly encouraged. Sites need not undertake the full multi-season campaign to contribute substantive value. Any additional intercomparison data will provide either additional training datasets or a means to independently validate results and ensure that any geographical effects have been adequately accounted for. Sites should contact the Lead Centre staff (lead author) to initiate a discussion around data submission requirements.

The participation of experts in the analysis of the results is strongly encouraged. Research results are likely to be more robust and comprehensive after accounting for a broad range of user inputs. The GRUAN community, although broadly diverse, is likely missing some important types of expertise. The GRUAN Lead Centre and Working Group chairs can provide letters of support and further information to investigators wishing to apply for grant support to aid their involvement in the analysis of the transition from the RS92 to other models of radiosonde.

The dissemination and outreach of results leading to an impact for both NRT and long-term applications will require sustained community engagement. It is important that the research results translate to real-world applications, and that will ultimately require user uptake.

\section{Summary and outlook}

In this paper we have described the ongoing GRUAN-wide coordinated approach to managing the change from the Vaisala RS92 to the RS41 as an operational radiosonde system within GRUAN. Since the network's goal is to provide long-term reference-quality observations of ECVs such as temperature and water vapor for the purpose of, e.g., climate monitoring, it is vital that this change of measurement system does not introduce discontinuities or inhomogeneities in the GRUAN data records. The majority of the 27 GRUAN sites were launching the RS92 as their operational radiosonde until its production ceased in late 2017; most of these sites have now switched to the RS41.

Such a large-scale change in instrumentation is unprecedented in the history of GRUAN and poses a challenge for the network. To ensure the integrity of the data record before and after the transition, it is necessary to fully understand and characterize the differences, the bias adjustment, and measurement uncertainties between the RS92 and RS41 radiosondes. Within GRUAN several different but aligned programs are generating a body of knowledge to underpin the RS92-RS41 transition, involving laboratory characterization of measurement errors due to external factors (e.g., solar radiation, time lag), extensive twin sounding studies with RS92 and RS41 on the same balloon, and comparison with ancillary measurements.

Conducting regular twin soundings for a period of 2 years is considered sufficient to capture seasonality in the differences. Since not all sites are able to implement such an extended intercomparison program, burden-sharing is employed, whereby at sites with similar climatological condi- 
tions, only one site needs to perform the intercomparisons. All data relevant to the RS92-RS41 transition are archived in a scientific database that will be accessible to the scientific community for external scrutiny, enabling transparency and traceability. These data include radiosoundings, collocated satellite observations, and other ancillary measurements, as well as data from laboratory measurements. Furthermore, data from intercomparison studies performed at several nonGRUAN sites have been shared with GRUAN by cooperating meteorological services and institutes, and these are also included in the database.

Preliminary analysis of the laboratory experiments indicates that the manufacturer calibrations of the RS41 temperature and humidity sensors are more accurate than for the RS92. Comparison with external references shows calibration uncertainties of $<0.2 \mathrm{~K}$ for temperature and $<$ $1.5 \% \mathrm{RH}$ for the humidity sensor. Preliminary analysis of 224 RS92-RS41 twin soundings performed at Lindenberg Observatory shows that differences between RS92-GDP.2 and Vaisala-processed RS41 nighttime temperature measurements are smaller than $0.1 \mathrm{~K}$ over the entire profile. However, daytime temperature differences in the stratosphere increase steadily with altitude, with $T_{\mathrm{RS} 92-G D P .2} 0.6 \mathrm{~K}$ higher than $T_{\mathrm{RS} 41}$ at $35 \mathrm{~km}$. RH values measured by the RS41 in the troposphere are up to $8 \%$ higher. These higher $\mathrm{RH}_{\mathrm{RS} 41}$ values are consistent with the analysis of satellite-radiosonde collocations. A comprehensive analysis of all twin soundings performed within GRUAN, which will also evaluate the effect of, e.g., climatological factors and will also include ancillary data, is ongoing.

Commensurate with the importance of detailed and comprehensive documentation to GRUAN's operations, the RS92-RS41 transition will be extensively documented to ensure traceability of the process. Furthermore, the documentation will help to convey the experience and knowledge gathered to other networks to aid them in managing any changes in their operational radiosonde systems. Future publications will report the results of the characterization of the RS92RS41 differences from various perspectives, and a final publication will evaluate the impact of the RS92-RS41 transition on GRUAN data records.

Data availability. The data from the laboratory experiments that were used for Figs. 4-7 and 9-11 are stored in a permanent repository with digital object identifier (DOI) https://doi.org/10.5676/GRUAN/dpkg-2019-1 (Dirksen and Sommer, 2019). The data from the radiosonde-satellite intercomparison that were used for Fig. 8 are stored in a permanent repository with digital object identifier (DOI) https://doi.org/10.5676/GRUAN/dpkg-2020-1 (Reale and Brown, 2020).
Author contributions. RJD designed and analyzed the laboratory experiments. MS performed the data collection of RS92-RS41 twin soundings, with data analysis by RJD. TR performed the analysis of radiosonde vs. ancillary data. RJD prepared the paper with contributions from all co-authors.

Competing interests. The authors declare that they have no conflict of interest.

Acknowledgements. The authors wish to thank David Smyth of Maynooth University and other members of the GRUAN community for their contribution to the discussion of the GRUAN change management, which greatly helped to improve this paper.

Review statement. This paper was edited by Maria Genzer and reviewed by two anonymous referees.

\section{References}

Bodeker, G. E., Bojinski, S., Cimini, D., Dirksen, R. J., Haeffelin, M., Hannigan, J. W., Hurst, D. F., Leblanc, T., Madonna, F., Maturilli, M., Mikalsen, A. C., Philipona, R., Reale, T., Seidel, D. J., Tan, D. G. H., Thorne, P. W., Vömel, H., and Wang, J.: Reference upper-air observations for climate: From concept to reality, B. Am. Meteorol. Soc., 97, 123-135, 2016.

Bojinski, S., Verstraete, M., Peterson, T. C., Richter, C., Simmons, A., and Zemp, M.: The concept of Essential Climate Variables in support of climate research, applications, and policy, B. Am. Meteorol. Soc., 95, 1431-1443, 2014.

Brunamonti, S., Jorge, T., Oelsner, P., Hanumanthu, S., Singh, B. B., Kumar, K. R., Sonbawne, S., Meier, S., Singh, D., Wienhold, F. G., Luo, B. P., Boettcher, M., Poltera, Y., Jauhiainen, H., Kayastha, R., Karmacharya, J., Dirksen, R., Naja, M., Rex, M., Fadnavis, S., and Peter, T.: Balloon-borne measurements of temperature, water vapor, ozone and aerosol backscatter on the southern slopes of the Himalayas during StratoClim 2016-2017, Atmos. Chem. Phys., 18, 15937-15957, https://doi.org/10.5194/acp-18-15937-2018, 2018.

Calbet, X., Peinado-Galan, N., Rípodas, P., Trent, T., Dirksen, R., and Sommer, M.: Consistency between GRUAN sondes, LBLRTM and IASI, Atmos. Meas. Tech., 10, 2323-2335, https://doi.org/10.5194/amt-10-2323-2017, 2017.

Dirksen, R. and Sommer, M.: Data package related to article "Progress in managing the transition from the RS92 to the Vaisala RS41 as the operational radiosonde within the GCOS Reference Upper-Air Network", https://doi.org/10.5676/GRUAN/dpkg-2019-1, 2019.

Dirksen, R. J., Sommer, M., Immler, F. J., Hurst, D. F., Kivi, R., and Vömel, H.: Reference quality upper-air measurements: GRUAN data processing for the Vaisala RS92 radiosonde, Atmos. Meas. Tech., 7, 4463-4490, https://doi.org/10.5194/amt-7-4463-2014, 2014.

Edwards, D., Anderson, G., Oakley, T., and Gault, P.: Met Office Intercomparison of Vaisala RS92 and RS41 Radiosondes, Tech. Rep., UKMO, available at: https://www.vaisala.com/ 
sites/defaults/files/documents/Met_Office_Intercomparison_of_ Vaisala_RS41_and_RS92_Radiosondes.pdf, (last access: 29 July 2020), 2014.

GCOS: The GCOS reference upper air network (GRUAN) Manual, Tech. Rep. 170, WMO/WIGOS Technical Report 201302, available at: https://library.wmo.int/index.php?lvl=notice display\&id=15181\#.XyF0pDXgqUl (last access: 29 July 20120), 2013a.

GCOS: The GCOS reference upper air network (GRUAN) Guide, Tech. Rep. 171, WMO/WIGOS Technical Report 2013-03, available at: https://library.wmo.int/index.php?lvl=notice_display\& id=15182\#.XyF06TXgqU (last access: 29 July 20120), 2013b.

Greenspan, L.: Humidity Fixed Points of Binary Saturated Aqueous Solutions, J. Res. NBS A Phys. Ch., 81, 89-96, 1977.

Hurst, D. F., Read, W. G., Vömel, H., Selkirk, H. B., Rosenlof, K. H., Davis, S. M., Hall, E. G., Jordan, A. F., and Oltmans, S. J.: Recent divergences in stratospheric water vapor measurements by frost point hygrometers and the Aura Microwave Limb Sounder, Atmos. Meas. Tech., 9, 4447-4457, https://doi.org/10.5194/amt-9-4447-2016, 2016.

Immler, F. J., Dykema, J., Gardiner, T., Whiteman, D. N., Thorne, P. W., and Vömel, H.: Reference Quality Upper-Air Measurements: guidance for developing GRUAN data products, Atmos. Meas. Tech., 3, 1217-1231, https://doi.org/10.5194/amt-3-1217-2010, 2010.

Jauhiainen, H., Fujiwara, M., Philipona, R., Dirksen, R., Hurst, D. F., Kivi, R., Vömel, H., Demoz, B., Kizu, N., Oakley, T., Shimizu, K., Maturilli, M., Leblanc, T., Madonna, F., and Querel, R.: GRUAN Technical document 7 - Review of Multiplepayload Radiosonde Sounding Configurations for Determining Best-Practice Guidance for GRUAN Sites, Tech. Rep., GRUAN Lead Centre, Lindenberg, version 1.0, available at: https://www. gruan.org/gruan/editor/documentation/gruan/td/gruan-td-7/ (last access: 29 July 2020), 2016.

Jensen, M. P., Holdridge, D. J., Survo, P., Lehtinen, R., Baxter, S., Toto, T., and Johnson, K. L.: Comparison of Vaisala radiosondes RS41 and RS92 at the ARM Southern Great Plains site, Atmos. Meas. Tech., 9, 3115-3129, https://doi.org/10.5194/amt-9-31152016, 2016.

Kawai, Y., Katsumata, M., Oshima, K., Hori, M. E., and Inoue, J.: Comparison of Vaisala radiosondes RS41 and RS92 launched over the oceans from the Arctic to the tropics, Atmos. Meas. Tech., 10, 2485-2498, https://doi.org/10.5194/amt10-2485-2017, 2017.

Kizu, N., Sugidachi, T., Kobayashi, E., Hoshino, S., Shimizu, K., Maeda, R., and Fujiwara, M.: GRUAN Technical Document 5 - Technical characteristics and GRUAN data processing for the Meisei RS-11G and iMS-100 radiosondes, Tech. Rep., GRUAN Lead Centre, Lindenberg, version 1.0, available at: https:// www.gruan.org/documentation/gruan/td/gruan-td-5 (last access: 29 July 2020), 2018.

Kobayashi, E., Noto, Y., Wakino, S., Yoshii, H., Ohyoshi, T., Saito, S., and Baba, Y.: Comparison of Meisei RS2-91 Rawinsondes and Vaisala RS92-SGP Radiosondes at Tateno for the Data Continuity for Climatic Data Analysis, J. Meteorol. Soc. Jpn. Ser. II, 90, 923-945, 2012.

Kobayashi, E., Hoshino, S., Iwabuchi, M., Sugidachi, T., Shimizu, K., and Fujiwara, M.: Comparison of the GRUAN data products for Meisei RS-11G and Vaisala RS92-SGP radiosondes at
Tateno $\left(36.06^{\circ} \mathrm{N}, 140.13^{\circ} \mathrm{E}\right)$, Japan, Atmos. Meas. Tech., 12, 3039-3065, https://doi.org/10.5194/amt-12-3039-2019, 2019.

Merlone, A., Lopardo, G., Sanna, F., Bell, S., Benyon, R., Bergerud, R. A., Bertiglia, F., Bojkovski, J., Böse, N., Brunet, M., Cappella, A., Coppa, G., del Campo, D., Dobre, M., Drnovsek, J., Ebert, V., Emardson, R., Fernicola, V., Flakiewicz, K., Gardiner, T., Garcia-Izquierdo, C., Georgin, E., Gilabert, A., Grykałowska, A., Grudniewicz, E., Heinonen, M., Holmsten, M., Hudoklin, D., Johansson, J., Kajastie, H., Kaykısızlı, H., Klason, P., Kňazovická, L., Lakka, A., Kowal, A., Müller, H., Musacchio, C., Nwaboh, J., Pavlasek, P., Piccato, A., Pitre, L., de Podesta, M., Rasmussen, M. K., Sairanen, H., Smorgon, D., Sparasci, F., Strnad, R., Szmyrka-Grzebyk, A., and Underwood, R.: The MeteoMet project - metrology for meteorology: challenges and results, Meteorol. Appl., 22, 820-829, https://doi.org/10.1002/met.1528, 2015.

Merlone, A., Sanna, F., Beges, G., Bell, S., Beltramino, G., Bojkovski, J., Brunet, M., Del Campo, D., Castrillo, A., Chiodo, N., Colli, M., Coppa, G., Cuccaro, R., Dobre, M., Drnovsek, J., Ebert, V., Fernicola, V., Garcia-Benadí, A., Garcia-Izquierdo, C., Gardiner, T., Georgin, E., Gonzalez, A., Groselj, D., Heinonen, M., Hernandez, S., Högström, R., Hudoklin, D., Kalemci, M., Kowal, A., Lanza, L., Miao, P., Musacchio, C., Nielsen, J., Nogueras-Cervera, M., Oguz Aytekin, S., Pavlasek, P., De Podesta, M., Rasmussen, M., Del-Río-Fernández, J., Rosso, L., Sairanen, H., Salminen, J., Sestan, D., Šindelářová, L., Smorgon, D., Sparasci, F., Strnad, R., Underwood, R., Uytun, A., and Voldan, M.: The MeteoMet2 project - Highlights and results, Meas. Sci. Technol., 29, 025802, https://doi.org/10.1088/13616501/aa99fc, 2018.

Miloshevich, L. M., Paukkunen, A., Vömel, H., and Oltmans, S. J.: Development and Validation of a Time-Lag Correction for Vaisala Radiosonde Humidity Measurements, J. Atmos. Ocean. Technol., 21, 1305-1327, https://doi.org/10.1175/15200426(2004)021<1305:DAVOAT>2.0.CO;2, 2004.

Musacchio, C., Bellagarda, S., Maturilli, M., Graeser, J., Vitale, V., and Merlone, A.: Arctic metrology: calibration of radiosondes ground check sensors in Ny-Ålesund, Meteorol. Appl., 22, 854860, https://doi.org/10.1002/met.1506, 2015.

Nash, J., Oakley, T., Vömel, H., and Wei, L.: WMO Intercomparison of High Quality Radiosonde Systems Yangjiang, China, 12 July-3 August 2010, Tech. Rep., WMO, available at: https://www.wmo.int/pages/prog/www/IMOP/publications/ IOM-107_Yangjiang.pdf (last access: 29 July 2020), WMO/TDNo. 1580, Instruments And Observing Methods Report No. 107, 2011.

Ning, T., Wang, J., Elgered, G., Dick, G., Wickert, J., Bradke, M., Sommer, M., Querel, R., and Smale, D.: The uncertainty of the atmospheric integrated water vapour estimated from GNSS observations, Atmos. Meas. Tech., 9, 79-92, https://doi.org/10.5194/amt-9-79-2016, 2016.

Peterson, T. C. and Durre, I.: A Climate Continuity Strategy for the Radiosonde Replacement System Transition, available at: https://ams.confex.com/ams/84Annual/techprogram/paper_ 71705.htm (last access: 2 September 2019), 2004.

Reale, T., Sun, B., Tilley, F. H., and Pettey, M.: The NOAA Products Validation System (NPROVS), J. Atmos. Ocean. Technol., 29, 629-645, https://doi.org/10.1175/JTECH-D-11-00072.1, 2012. 
Reale, T. and Brown, C.: Data package related to the article "Managing the transition from Vaisala RS92 to RS41 radiosondes within the Global Climate Observing System Reference UpperAir Network (GRUAN): a progress report", GRUAN Lead Centre, https://doi.org/10.5676/GRUAN/dpkg-2020-1, 2020.

Rex, M.: StratoClim, Stratospheric and upper tropospheric processes for better climate predictions, available at: http://www. stratoclim.org (last access: 15 January 2019), 2014.

Seidel, D. J., Berger, F. H., Immler, F., Sommer, M., Vömel, H., Diamond, H. J., Dykema, J., Goodrich, D., Murray, W., Peterson, T., Sisterson, D., Thorne, P., and Wang, J.: Reference Upper-Air Observations for Climate: Rationale, Progress, and Plans, B. Am. Meteorol. Soc., 90, 361-369, 2009.

Sun, B., Reale, A., Tilley, F., Pettey, M., Nalli, N., and Barnet, C.: Assessment of NUCAPS S-NPP CrIS/ATMS Sounding Products Using Reference and Conventional Radiosonde Observations, abstract AMS, available at: https://ams.confex. com/ams/97Annual/webprogram/Paper313881.html (last access: 29 July 2020), 2016.

Tobin, D. C., Revercomb, H. E., Knuteson, R. O., Lesht, B. M., Strow, L. L., Hannon, S. E., Feltz, W. F., Moy, L. A., Fetzer, E. J., and Cress, T. S.: Atmospheric Radiation Measurement site atmospheric state best estimates for Atmospheric Infrared Sounder temperature and water vapor retrieval validation, J. Geophys. Res., 111, d09S14, https://doi.org/10.1029/2005JD006103, 2006.
Vaisala: CAL4 Calibration machine Traceability and Uncertainty, Technical Document DOC210645, Vaisala DCO210645, 2002.

von Rohden, C., Sommer, M., and Dirksen, R.: GRUAN Technical Note 7 - Rigging recommendations for dual radiosonde soundings, Tech. Rep., GRUAN Lead Centre, Lindenberg, version 1.0, available at: https://www.gruan.org/gruan/editor/documents/ gruan/GRUAN-TN-7_Comparison_setup_v1.0_final.pdf (last access: 29 July 2020), 2016.

WMO: Manual on the Global Observing System, World Meteorological Organization, Secretariat of the World Meteorological Organization, Geneva, Switzerland, Geneva, WMO-No. 544, available at: https://www.wmo.int/pages/prog/www/OSY/ Manuals_GOS.htm (last access: 29 July 2020), 2017. 